grade spread, and we can see no advantage in using the larger volume.

We suggest that the $10 \%$ hydrocortisone foam may be useful in treating patients with distal ulcerative colitis that is not necessarily confined to the rectum.

MJGF is supported by a grant from the Wellcome Trust and MDR by the joint research board of St Bartholomew's Hospital.

\section{References}

1 Truelove, S C, British Medical fournal, 1956, 2, 1267.

2 Truelove, S C, British Medical fournal, 1958, 2, 1027.
3 Watkinson, G, British Medical fournal, 1958, 2, 1077.

4 Matts, S G F, British Medical fournal, 1961, 1, 165.

5 Multicentre trial, British Medical fournal, 1971, 3, 84.

6 Matts, S G F, and Gaskell, K H, British Medical fournal, 1961, 2, 614.

7 Truelove, S C, British Medical fournal, 1960, 1, 464.

8 Scherl, W D, and Scherl, B A, Diseases of the Colon and Rectum, 1973, 16, 149.

9 Clark, M L, Practitioner, 1977, 219, 103.

10 Farthing, M J G, Rutland, M D, and Clark, M L, Gut, 1979, 20, A453.

${ }^{11}$ Hay, D J, Sharma, H, and Irving, M H, British Medical fournal, 1979, 1, 1751 .

12 Swarbrick, E T, Loose, H, and Lennard-Jones, J E, Proceedings of the Royal Society of Medicine, 1974, 67, 753.

(Accepted 2 August 1979)

\title{
Inflammatory bowel disease in the West Indies
}

\author{
COURTENAY BARTHOLOMEW, ALAN BUTLER
}

British Medical fournal, 1979, 2, 824-825

\section{Summary and conclusions}

Inflammatory bowel disease is generally assumed to be rare among negroes and Indians. Over 10 years 34 cases of ulcerative colitis and 14 cases of Crohn's disease were seen in one medical and one surgical unit in Port-ofSpain, Trinidad. Twenty-six patients were Negroes, 18 were Indians, three were of mixed race, and one was Caucasian. In many of these patients the disease was extensive and several of those with Crohn's disease suffered severe complications.

The assumption that inflammatory bowel disease is rare among West Indians of African and Indian origin therefore seems to be wrong.

\section{Introduction}

The cause of both ulcerative colitis and Crohn's disease is still inconclusive, but several studies point to an association between these two diseases and also to a genetic and ethnic background. There has been little documentary evidence of inflammatory bowel disease in Asians and Africans and it is thought to be essentially a disease of temperate zones. ${ }^{1}$ Recently O'Donoghue and Clark $^{2}$ reported five patients with inflammatory bowel disease in West Indians of African stock living in Britain and stated that these diseases had not been reported in West Indians. Their patients were all Jamaicans, two of whom were born in the United Kingdom, and they suggested that exposure to environmental factors in the United Kingdom may have accounted for these diseases developing in West Indians there. We describe here 48 cases of inflammatory bowel disease in Trinidadians born and resident in Trinidad and Tobago and seen in one medical and one surgical unit at the General Hospital, Port-

\footnotetext{
University Department of Medicine, General Hospital, Port-ofSpain, Trinidad COURTENAY BARTHOLOMEW, MD, FRCPED, professor of medicine

University Department of Surgery, General Hospital, Port-ofSpain, Trinidad

ALAN BUTLER, MB, FRCS, senior lecturer in surgery
}

of-Spain, during 10 years from 1968. No attempt was made to determine the total number of hospital admissions in the island of proved cases of inflammatory bowel disease.

\section{Patients}

Thirty-four cases of ulcerative colitis and 14 cases of Crohn's disease were seen. All the patients with colitis (13 men, 21 women) presented with diarrhoea with blood and mucus in the stools. Their ages ranged from 11 to 66 years, and 20 patients were under the age of 29 . Twenty-one were Negroes (9 men) and 10 Indians ( 3 men). As bacillary and amoebic dysentery are sometimes seen in Trinidad and Tobago fresh stools were examined in all cases for Shigellae, Salmonellae, and Entamoeba histolytica. The results were negative in each case. None the less, a therapeutic trial of metronidazole was given in most cases without any clinical response. On the other hand, all the patients responded to prednisone and sulphasalazine.

The diagnosis of ulcerative colitis was made at sigmoidoscopy and by radiological examination with confirmation by histology. In 16 cases there was total colitis at the time of presentation, in 17 a distal colitis, and in one case only the rectum was affected (ulcerative proctitis). Two patients had extensive pseudopolypoid transformation of the mucosa, one developed cirrhosis of the liver with intrahepatic cholestasis, and another had an adenocarcinoma of the sigmoid colon as a complication of the colitis. One patient with severe total colitis died from a pulmonary embolism. There did not appear to be any socioeconomic preference, although many of the patients were above average in intelligence.

The 14 patients with Crohn's disease (9 men, 5 women) were aged 11 to 45 years, and six presented below the age of 29. Six were Negroes, seven were Indians, and one was Caucasian. Five patients presented with regional ileitis, one with a jejunocolitis, six with ileocolitis, and two with granulomatous colitis. Seven presented with or developed fistulas and two had perineal skin ulceration, which was very extensive in one case. In the Caucasian, a 40 -year-old man, a contiguous and fistulous lesion from a jejunitis produced a localised granulomatous colitis in the transverse colon. An external abdominal fistula and an adenocarcinoma of the jejunum eventually developed, from which the patient died. All the patients had normal chest radiographs and there was no evidence of tuberculosis. The diagnoses of these patients were confirmed by laparotomy and histology. Bowel resections were done on 12 patients.

\section{Discussion}

Ulcerative colitis is very rare in black Africa, and in 1960 Trowell ${ }^{3}$ wrote "there is no report in the literature of an African suffering from this disease and none has been encountered in 
the practice of the Mulago Hospital." From Makerere University College, Uganda, Billinghurst and Welchman ${ }^{4}$ reported the first detailed account of ulcerative colitis developing in four Africans in tropical Africa. Inspection of the medical records of the Lagos University Teaching Hospital for 1962-8 showed only one patient with a diagnosis of ulcerative colitis that could be substantiated. ${ }^{5}$ Tandon $e t a l^{6}$ reported 65 cases of ulcerative colitis in two and a half years in populous northern India and concluded that the disease was not as rare as was thought in Indians. Chuttani et al, ${ }^{7}$ who studied the medical records of leading hospitals in different parts of India for 1955-60, also showed that ulcerative colitis was not rare in that part of the world, but they claimed that it was a mild disease when compared with that in Western series. Wye Poh Fung et $a l^{8}$ from Singapore, where $75^{\circ}$ of the population of 2 million are Chinese and $8^{\circ}$. Indian, documented 10 patients, five Chinese and five Indians, with non-specific ulcerative colitis; this was probably the first report of this disease in Chinese. Terry and Raje $^{9}$ recently described 32 unpublished cases of ulcerative colitis in Jamaica.

The reported pattern for Crohn's disease seems to be more clear-cut. Only five cases of Crohn's disease were observed in the Harlem Hospital during 1936-49, ${ }^{11}$ and an epidemiological and demographic study of inflammatory bowel disease based on a computerised file of all patients followed up at the University of Chicago found only 23 cases of Crohn's disease in blacks among 1557 patients with inflammatory bowel disease. ${ }^{12}$ Crohn's disease is also rare in Indians in India and Pakistan. ${ }^{13}$

Trinidad and Tobago is a very cosmopolitan island with a population of 1.2 million people, $42^{\circ}{ }_{0}$ of whom are Negroes,
$40 \%$ Indians, $0.9 \%$ Chinese, $1 \%$ white, and $14 \%$ mixed. There seems to be no significant ethnic preference for these diseases among the Negroes and Indians of the island, suggesting perhaps a common environmental factor. The course of inflammatory bowel disease in Trinidadians cannot be described as mild, for in many cases the disease was extensive and the complications severe. Inflammatory bowel disease does occur in West Indians of both African and Indian stock who have not migrated to the United Kingdom and so environmental factors abroad do not necessarily play a part in the pathogenesis of this disease in these people.

\section{References}

${ }^{1}$ Melrose, A G, Gastroenterology, 1955, 29, 1055.

2 O'Donoghue, D P, and Clark, M L, British Medical fournal, 1976, 2, 796.

3 Trowell, H C, Non-infective Disease in Africa. London, Arnold, 1960.

${ }^{4}$ Billinghurst, J R, and Welchman, J M, British Medical fournal, 1966, $1,211$.

5 Naish, J M, Batchvarov, B D, and Lawoyin, V L, Gut, 1970, 11, 38.

6 Tandon, B N, et al, Gut, 1965, 6, 448.

7 Chuttani, H K, et al, British Medical fournal, 1967, 4, 204.

${ }^{8}$ Wye Poh Fung, et al, Medical fournal of Australia, 1971, 2, 361.

9 Terry, S, and Raje, D, paper read at 22nd Scientific Meeting of the Commonwealth Caribbean Medical Research Council, Belize, 1977.

${ }^{10}$ Crohn, B B, Ginsburg, L, and Oppenheimer, G D, fournal of the American Medical Association, 1932, 99, 1323.

${ }^{11}$ Marks, J A, and Fink, S, Gastroenterology Review, 1949, 16, 623.

12 Samuels, A D, et al, Digestive Diseases, 1974, 19, 156.

13 Woodruff, A W, editor, Alimentary and Haematological Aspects of Tropical Diseases, p 76. London, Arnold, 1970.

(Accepted 20 fuly 1979)

\title{
Finger clubbing in inflammatory bowel disease: its prevalence and pathogenesis
}

\author{
G KITIS, H THOMPSON, R N ALLAN
}

British Medical fournal, 1979, 2, 825-828

\section{Summary and conclusions}

Finger clubbing, measured objectively by using the hyponychial angle, was present in 75 out of $200(38 \%)$ patients with Crohn's disease, 15 out of $103(15 \%)$ with ulcerative colitis, and two out of $24(8 \%)$ with proctitis. In Crohn's disease and ulcerative colitis the hyponychial angle was significantly correlated with both disease activity and the extent of fibrosis in the resected specimens from 47 surgically treated patients. The prevalence of finger clubbing in patients with macroscopic disease within the area of the gut innervated by the vagus nerve was significantly higher than that in patients in whom the disease was confined to the distal colon and rectum. Finger clubbing in patients with Crohn's disease tended to regress after resection of macroscopic disease.

Gastroenterology Unit, General Hospital, Birmingham B4 6NH G KITIS, MRCP, research fellow

R N ALLAN, MD, MRCP, consultant physician

University of Birmingham, Birmingham

H THOMPSON, MRCPATH, reader in pathology
It is concluded that finger clubbing is significantly commoner in Crohn's disease than ulcerative colitis. The focal stimuli for finger clubbing include mucosal inflammatory change and fibrosis mediated by the vagus and possibly other autonomic pathways acting as the afferent arc of a finger-clubbing reflex.

\section{Introduction}

Trousseau ${ }^{1}$ suggested the term finger clubbing for changes in the fingers first described by Hippocrates. ${ }^{2}$ Its pathogenesis remains unknown. The clinical assessment of finger clubbing is often unreliable and subject to errors made by different or even the same observers. ${ }^{3}$ Measurements taken from digital casts have shown that the hyponychial and profile angles provide the best objective evaluation of finger clubbing. ${ }^{4}$ Of the two, the hyponychial angle, which also incorporates the profile angle, is the more reliable (see fig 1). The hyponychial and profile angles can now be measured clinically simply and effectively with the finger-clubbing shadowgraph. ${ }^{5}$ The normal range has been established in adults and children, and the method used in studies of finger clubbing in children with thalassaemia, ${ }^{6}$ cystic fibrosis, bronchial asthma, and congenital heart disease.

The association between finger clubbing and inflammatory bowel disease is well recognised, ${ }^{8-12}$ and patients with both conditions provide a useful model when studying pathogenesis. 